Received: 31.08 .2018

Revised: 28.09.2018

Accepted: 26.10 .2018

DOI: $10.17804 / 2410-9908.2018 .5 .086-105$

\title{
EFFECT OF THE COMPOSITION OF ABSORBING COATINGS ON THE STRUCTURE AND PROPERTIES OF A CAST ALUMINUM ALLOY SUBJECTED TO SURFACE LASER HEAT TREATMENT
}

\author{
R. A. Savrai ${ }^{1, a^{*}}$, I. Yu. Malygina ${ }^{1, \text { b) }}$, A. V. Makarov ${ }^{1,2,3, c)}$, A. L. Osintseva ${ }^{1, d)}$ \\ S. A. Rogovaya ${ }^{1, \text { e) }}$, N. A. Davydova ${ }^{1, \text { f) }}$ \\ ${ }^{1}$ Institute of Engineering Science, Ural Branch of the Russian Academy of Sciences, \\ 34 Komsomolskaya St., Ekaterinburg, 620049, Russia \\ ${ }^{2}$ M.N. Miheev Institute of Metal Physics, Ural Branch of the Russian Academy of Sciences, \\ 18 S. Kovalevskoy St., Ekaterinburg, 620108, Russia \\ ${ }^{3}$ B.N. Yeltsin Ural Federal University, 19 Mira St., Ekaterinburg, 620002, Russia

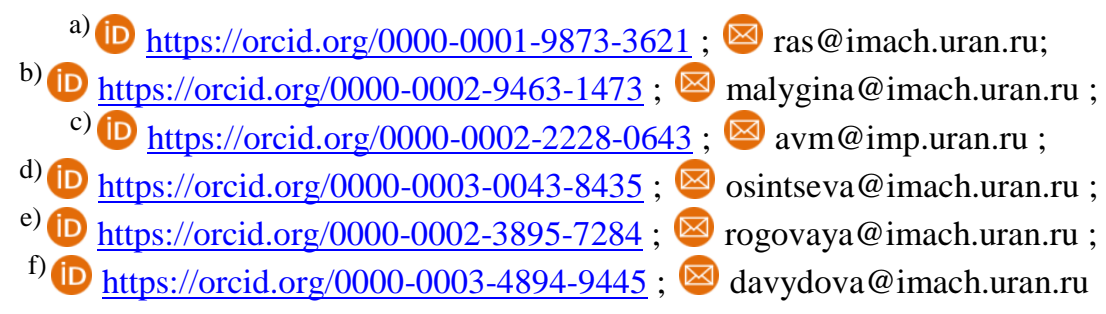 \\ "Corresponding author. E-mail: ras@imach.uran.ru \\ Address for correspondence: ul. Komsomolskaya, 34, Ekaterinburg, 620049, Russian Federation \\ Tel.:+7 (343) 3623014
}

The microstructure, microhardness, surface roughness and chemical composition of the AK7ch cast aluminum alloy are studied after surface laser heat treatment, which is performed using new dextrin-based absorbing coatings of different compositions, namely, composition 1 (the water solution of dextrin $+\mathrm{Na}_{2} \mathrm{O}\left(\mathrm{SiO}_{2}\right)_{\mathrm{n}}$ ) and composition 2 (the water solution of dextrin $+\mathrm{ZnO}$ ). It has been established that, for the best surface quality $(\mathrm{Ra}=1.03-3.60 \mu \mathrm{m})$ and the greatest depth $(0.7-1.16 \mathrm{~mm})$ of the molten zone to be achieved, it is expedient that laser heat treatment of the AK7ch alloy should be carried out using an absorbing coating of composition 1 , both with a $\mathrm{CO}_{2}$-laser (radiation wavelength $\left.\lambda=10.6 \mu \mathrm{m}\right)$ and a fiber laser $(\lambda=1.070 \mu \mathrm{m})$. At that, laser heat treatment decreases the sizes of $\alpha$-Al dendritic cells from $50-190 \mu \mathrm{m}$ to $5.0-11.5 \mu \mathrm{m}$ and the sizes of silicon crystals from 5-30 $\mu \mathrm{m}$ to $0.5-2.0 \mu \mathrm{m}$, whereas microhardness increases by a factor of 1.11-1.22 from that of the as-cast alloy $(90 \mathrm{HV} 0.025)$. An even distribution of alloying elements in the molten zone is also ensured.

Keywords: cast aluminum alloy, laser heat treatment, absorbing coating, microstructure, microhardness, surface roughness, chemical composition.

\section{Acknowledgment}

This work was done within the Complex Program of UB RAS, project no. 18-10-1-40, and within the state assignment of FASO Russia on the subject "Structure", no. AAAA-A18-118020190116-6.

Electron scanning and optical microscopy, as well as optical profilometry and microdurometry, were performed in the Plastometriya collective use center of the Institute of Engineering Science, UB RAS.

We appreciate the participation of $L$. A. Odintsova in the development of the compositions of the absorbing coatings and specimen processing by a fiber laser. 


\section{References}

1. Rogozhin M.V., Rogalin V.E., Krymskii M.I., Kaplunov I.A. On the possibility of increasing the service life of high-power laser optics through the use of polycrystalline diamond windows with a central monocrystalline area. Diagnostics, Resource and Mechanics of materials and structures, 2018, iss. 1, pp. 34-40. Available at: http://dream-journal.org/issues/2018-1/2018-1_132.html 2. Makarov A.V., Malygina I.Yu., Osintseva A.L. The effect of laser processing on the structure, wear resistance and fatigue properties of high-strength cast iron. Fizika i khimiya obrabotki materialov, 2006, no. 4, pp. 46-55. (In Russian).

3. Pugacheva N.B., Michurov N.S., Trushina E.B. Peculiarities of the structure of welded aluminum alloy joints. Diagnostics, Resource and Mechanics of materials and structures, 2015, iss. 5, pp. 58-71. Available at: http://dream-journal.org/issues/2015-5/2015-5_43.html

4. Makarov A.V., Soboleva N.N. Formation of wear-resistant NiCrBSi coatings by laser cladding and combined treatments. In: Perspektivnyye Materialy, t. 7: Uchebnoye posobiye [Advanced Materials, ed. by D.L. Merson, vol. 7: Educational Book]. Tolyatti, TGU Publ., 2017, 292 p. (In Russian).

5. Makarov A.V., Soboleva N.N., Malygina I.Yu., Osintseva A.L. Formation of wear-resistant chromium-nickel coating with extra high thermal stability by combined laser-and-heat treatment. Metal Science and Heat Treatment, 2015, vol. 57, nos. 3-4, pp. 161-168. DOI: 10.1007/s11041015-9856-8.

6. Makarov A.V., Savrai R.A., Osintseva A.L., Malygina I.Yu. Effect of chemical composition on the tribological properties of chromium-nickel coatings obtained by gas-powder laser cladding. Izvestiya Chelyabinskogo Nauchnogo Tsentra UrO RAN, 2009, iss. 2 (44), pp. 28-33. (In Russian).

7. Makarov A.V., Gorkunov E.S., Malygina I.Yu., Kogan L.Kh., Savrai R.A., Osintseva A.L. Eddy-current testing of the hardness, wear resistance, and thickness of coatings prepared by gaspowder laser cladding. Russian Journal of Nondestructive Testing, 2009, vol. 45, iss. 11, pp. 797-805. DOI: $10.1134 / \mathrm{S} 1061830909110060$.

8. Soboleva N.N., Malygina I.Yu., Osintseva A.L., Pozdeeva N.A. Effect of microstructure and phase composition on the tribological properties of NiCrBSi laser coatings. Izvestiya Samarskogo Nauchnogo Tsentra RAN, 2011, vol. 13, iss. 4 (3), pp. 869-873. (In Russian).

9. Makarov A.V., Soboleva N.N., Malygina I.Yu. Role of the strengthening phases in abrasive wear resistance of laser-clad NiCrBSi coatings. Journal of Friction and Wear, 2017, vol. 38, iss. 4, pp. 272-278. DOI: 10.3103/S1068366617040080.

10. Makarov A.V., Soboleva N.N., Malygina I.Yu., Osintseva A.L. The formation of a NiCrBSi-TiC composite coating with high abrasive wear resistance by the method of gaspowder laser cladding. Uprochnyayushchie Tekhnologii i Pokrytiya, 2013, iss.11 (107), pp. 38-44. (In Russian).

11. Makarov A.V., Soboleva N.N., Malygina I.Yu., Osintseva A.L. The tribological performances of a NiCrBSi-TiC laser-clad composite coating under abrasion and sliding friction. Diagnostics, Resource and Mechanics of materials and structures, 2015, iss. 3, pp. 83-97. Available at: http:/dream-journal.org/Issues/2015-3/2015-3_33.html

12. Savrai R.A., Makarov A.V., Soboleva N.N., Malygina I.Yu., Osintseva A.L. Contact endurance of NiCrBSi coatings obtained by gas-powder laser cladding. Obrabotka metallov, 2014, iss. 4 (65), pp. 43-51. (In Russian).

13. Savrai R.A., Makarov A.V., Gorkunov E.S., Kogan L.Kh., Soboleva N.N., Malygina I.Yu., Osintseva A.L. Eddy-current testing of fatigue degradation under contact loading of NiCrBSi coatings obtained through gas-powder laser cladding. Russian Journal of Nondestructive Testing, 2015, vol. 51, iss. 11, pp. 692-704. DOI: 10.1134/S1061830915110042. 
14. Savrai R.A., Makarov A.V., Soboleva N.N., Malygina I.Yu., Osintseva A.L. The behavior of gas powder laser clad NiCrBSi coatings under contact loading. Journal of Materials Engineering and Performance, 2016, vol. 25, iss. 3, pp. 1068-1075. DOI: 10.1007/s11665-016-1925-7.

15. Savrai R.A., Makarov A.V., Gorkunov E.S., Soboleva N.N., Kogan L.Kh., Malygina I.Yu., Osintseva A.L., Davydova N.A. Eddy-current testing of the fatigue degradation of a gas powder laser clad $\mathrm{NiCrBSi}-\mathrm{Cr}_{3} \mathrm{C}_{2}$ composite coating under contact fatigue loading. In: AIP Conference Proceedings, 2017, vol. 1915, no. 040049, pp. 1-4. DOI: 10.1063/1.5017397.

16. Makarov A.V., Soboleva N.N., Savrai R.A., Malygina I.Yu. Improvement of micromechanical properties and wear resistance of Chromium-Nickel laser coating by friction finishing. Vektor Nauki TGU, 2015, iss.4 (34), pp. 60-67. DOI: 10.18323/2073-5073-2015-4-60-67 (In Russian).

17. Khodakovsky V.M. Technological aspects of the choice of equipment for laser hardening of parts. Vestnik Morskogo Gosudarstvennogo Universiteta. Seriya: Sudostroeniye i Sudoremont, 2011, iss. 47, pp. 8-13. (In Russian).

18. Kostritsky V.V., Lisovsky A.L. Increasing the absorptivity of a laser-affected surface metal layer by means of absorbing coatings. Vestnik Polotskogo Gosudarstvennogo Universiteta. Seriya V. Promyshlennost. Prikladnyye Nauki. Mashinostroeniye, 2013, iss. 3, pp. 97-101. (In Russian).

19. Shastin V.I. Ways of improving the efficiency of laser thermal hardening of iron-carbon alloys. Vestnik Altayskogo Gosudarstvennogo Agrarnogo Universiteta, 2015, iss. 11 (133), pp. 117-121. (In Russian).

20. Promyshlennoe primenenie lazerov [Industrial Application of Lasers, G. Kebnera, ed.]. Moscow, Mashinostroeniye Publ., 1988, 280 p. (In Russian).

21. Kovalenko V.S., Golovko L.V., Chernenko V.S. Uprochnenie i legirovanie detaley mashin luchom lazera [Hardening and Alloying of Machine Parts by a Laser Beam]. Kiev, Tekhnika Publ., 1990, 191 p. (In Russian).

22. Klimkov Yu.M., Mayorov V.S., Khoroshev M.V. Vzaimodeistvie lazernogo izlucheniya s veshchestvom: Uchebnoe posobie [Interaction of Laser Radiation with a Substance: Educational Book]. Moscow, MIIGAiK Publ., 2014, 108 p. (In Russian).

23. Grigoriyants A.G., Shiganov I.N., Misyurov A.I. Tekhnologicheskie protsessy lazernoy obrabotki: Uchebnoe posobie [Technological Processes of Laser Treatment: Educational Book, A.G. Grigoriyants ed.]. MGTU im. N.E. Baumana Publ., 2008, 664 p. (In Russian).

24. Predoi D. A study on iron oxide nanoparticles coated with dextrin obtained by coprecipitation. Digest Journal of Nanomaterials and Biostructures, 2007, vol. 2, no. 1, pp. 169-173.

25. Vizeman Frank L., Georgetown College, Basic Organic Chemistry, McGrawHill Company, New York [Fundamentals of organic chemistry: Uchebnoe posobie, pod. red. A.A. Potekhina, SPb., Khimiya Publ., 1995, 464 p.].

26. Krishtal M.M., Ivashin P.V., Kolomiets P.V. Application of the microarc oxidation technology to the development of internal combustion engines with aluminum alloy cylinder blocks. Izvestiya Samarskogo Nauchnogo Tsentra RAN, 2010, vol. 12, iss.4, pp. 242-246. (In Russian).

27. Kalner V.D., Volgin V.I., Andriyakhin V.M., Sedunov V.K. Strengthening of the AL4 aluminum alloy by radiation of a $\mathrm{CO}_{2}$ laser. Poverkhnost: Fizika. Khimiya. Mekhanika, 1982, iss. 12, pp. 131-134. (In Russian).

28. Libenson M.N., Yakovlev E.B., Shandybina G.D. Vzaimodeystvie lazernogo izlucheniya $s$ veshchestvom (silovaya optika): uchebnoe posobie [Interaction of Laser Radiation with a Substance (power optics): part II: Laser Heating and Material Destruction: educational book, V.P. Veyko, ed.]. SPb., NIU ITMO Publ., 2014, 181 p. (In Russian).

29. Kuznetsov P.M., Fedorov V.A. Features of relief formation on the surface of metals in the zone affected by laser radiation. Vestnik Tolyattinskogo Gosudarstvennogo Universiteta, 2015, vol. 20, iss. 4, pp. 872-877. (In Russian). 
Подана в журнал: 31.08 .2018

УДК 669.715:621.785.5:621.789

DOI: $10.17804 / 2410-9908.2018 .5 .086-105$

\title{
ВЛИЯНИЕ СОСТАВА ПОГЛОЩАЮЩИХ ПОКРЫТИЙ НА СТРУКТУРУ И СВОЙСТВА ЛИТЕЙНОГО АЛЮМИНИЕВОГО СПЛАВА, ПОДВЕРГНУТОГО ПОВЕРХНОСТНОЙ ЛАЗЕРНОЙ ТЕРМИЧЕСКОЙ ОБРАБОТКЕ
}

\author{
Р. А. Саврай ${ }^{1,)^{*}}$, И. Ю. Малыгина ${ }^{1, \text { б) }}$, А. В. Макаров ${ }^{1,2,3, \text { в) }}$ А. Л. Осинцева ${ }^{1, \text { г) }}$, \\ С. А. Роговая ${ }^{1, \text { д) }}$, Н. А. Давыдова ${ }^{1, \text { e) }}$ \\ ${ }^{1}$ Федеральное государственное бюджетное учреждение науки Институт машиноведения \\ Уральского отделения Российской академии наук, \\ д. 34, ул. Комсомольская, г. Екатеринбург, 620049, Россия \\ ${ }^{2}$ Федеральное государственное бюджетное учреждение науки \\ Институт физики металлов имени М.Н. Михеева Уральского отделения Российской академии наук, \\ д. 18, ул. С. Ковалевской, г. Екатеринбург, 620108, Россия \\ ${ }^{3}$ Уральский Федеральный Университет имени Б.Н. Ельична, \\ д. 19, ул. Мира, Екатеринбург, 620002, Россия \\ a) iD https://orcid.org/0000-0001-9873-3621; 《 ras@imach.uran.ru; \\ б) iD https://orcid.org/0000-0002-9463-1473 ; malygina@imach.uran.ru ; \\ в) (iD https://orcid.org/0000-0002-2228-0643; ; avm@imp.uran.ru ; \\ г) (iD https://orcid.org/0000-0003-0043-8435 ; ه osintseva@imach.uran.ru ; \\ д) (iD https://orcid.org/0000-0002-3895-7284; ; rogovaya@imach.uran.ru ; \\ e) iD https://orcid.org/0000-0003-4894-9445 ; ه davydova@imach.uran.ru \\ * Ответственный автор. Электронная почта: ras@imach.uran.ru \\ Адрес для переписки: ул. Комсомольская, 34, Екатеринбург, Российская Федерация \\ Тел.: +7 (343) 3623014
}

Исследована микроструктура, микротвердость, шероховатость поверхности и химический состав литейного алюминиевого сплава АК7ч после поверхностной лазерной термической обработки с использованием новых поглощающих покрытий на основе декстрина составов 1 (водный раствор декстрина $\left.+\mathrm{Na}_{2} \mathrm{O}\left(\mathrm{SiO}_{2}\right)_{\mathrm{n}}\right)$ и 2 (водный раствор декстрина $+\mathrm{ZnO}$ ). Установлено, что для обеспечения наилучшего качества поверхности $(\mathrm{Ra}=1,03-3,60$ мкм) и наибольшей глубины $(0,75-1,16$ мм) зоны оплавления лазерную обработку сплава АК7ч целесообразно проводить с использованием поглощающего покрытия состава 1 с помощью как $\mathrm{CO}_{2}$-лазера (длина волны излучения $\lambda=10,6$ мкм), так и оптоволоконного лазера $(\lambda=1,070$ мкм). При этом в результате лазерной обработки размер дендритных ячеек $\alpha$-Al уменьшается от 50-190 мкм до 5,0-11,5 мкм, размер кристаллов кремния уменьшается от 5-30 мкм до 0,5-2,0 мкм, а микротвердость возрастает в 1,11-1,22 раза по сравнению со значением микротвердости сплава в исходном литом состоянии (90 HV0,025). Обеспечивается также равномерное распределение легирующих элементов в зоне оплавления.

Ключевые слова: литейный алюминиевый сплав, лазерная термическая обработка, поглощающее покрытие, микроструктура, микротвердость, шероховатость поверхности, химический состав.

\section{1. Введение}

Лазерная термическая обработка относится к современным способам повышения физико-механических свойств поверхности деталей машин. По сравнению с другими источниками нагрева лазерный луч имеет ряд существенных преимуществ, таких как значительную мощ- 
ность излучения, локальность воздействия, малую зону термического влияния, возможность обработки поверхности деталей в труднодоступных местах и высокую степень автоматизации процесса обработки. Наиболее широкое распространение получили $\mathrm{CO}_{2}$-лазеры [1], которые используются как для лазерной обработки [2], так и для сварки [3], и нанесения различных покрытий [4-16]. Кроме того, в последние годы появились экономически эффективные и технологичные оптоволоконные лазеры, коэффициент полезного действия которых достигает 30 \%, что в 6 раз выше, чем у $\mathrm{CO}_{2}$-лазеров [17]. Основная проблема при лазерной обработке металлических материалов - высокий коэффициент отражения и, соответственно, низкий коэффициент поглощения лазерного излучения обрабатываемой поверхностью. Поэтому для проведения лазерной обработки металлов необходимо повышать их поглощательную способность.

Существует несколько способов повышения поглощательной способности металлов при лазерном воздействии, из которых наиболее эффективным является нанесение поглощающих покрытий. С использованием таких покрытий коэффициент поглощения лазерного излучения может быть повышен до 90 \% и более [18]. Поглощающие покрытия наносят на обрабатываемую поверхность различными методами: химическое оксидирование, фосфатирование [18] и сульфидирование [2, 19], химическое травление [18], нанесение металлических порошков в вакууме [18], распыление или окрашивание $[18,20]$. При этом вещества, используемые в качестве поглощающих покрытий, должны отвечать следующим основным требованиям: экономичность, высокая поглощательная способность излучения, хорошая теплопроводность и термическая стойкость, высокая адгезия с металлом, легкость снятия с поверхности, а также технологичность $[18,20]$.

Большинство поглощающих покрытий разработано для сплавов на железной основе, поскольку изделия из сталей и чугунов наиболее часто подвергают лазерной термической обработке. Поглощающим покрытиям для лазерной обработки цветных сплавов уделяется значительно меньшее внимание. Во многом это обусловлено тем, что лазерная обработка алюминиевых сплавов сопряжена с более существенными трудностями вследствие высоких значений их теплоемкости, теплопроводности, электропроводности и коэффициента отражения лазерного излучения. Известно, что поглощательная способность материалов растет с уменьшением длины волны л лазерного излучения. Тем не менее у алюминиевых сплавов она остается недостаточно высокой даже при использовании коротковолнового лазерного излучения. В частности, поглощательная способность алюминия для излучения $\mathrm{CO}_{2}$-лазера $(\lambda=10,6$ мкм) составляет 0,019 , для излучения

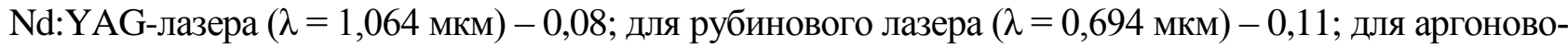
го лазера $(\lambda=0,488$ мкм) - 0,19 [21, 22]. Следовательно, для качественной лазерной обработки алюминиевых сплавов применение поглощающих покрытий является необходимым условием. В настоящее время с этой целью применяют анодирование для получения пленки $\mathrm{Al}_{2} \mathrm{O}_{3}$ на поверхности сплава, а также специальные покрытия типа ВМЛ на основе лака и ФС-1М на основе алюмохромфосфата, которое увеличивает коэффициент поглощения до $90 \%$ и применяется для лазерной обработки алюминиевых сплавов с оплавлением поверхности $[18,23]$. Однако необходимость повышения эффективности производства делает чрезвычайно актуальной проблему разработки поглощающих покрытий из более дешевых и широкодоступных материалов.

Цель данной работы - исследование микроструктуры, микротвердости, шероховатости поверхности и химического состава литейного алюминиевого сплава АК7ч после поверхностной лазерной термической обработки с использованием новых поглощающих покрытий на основе декстрина. Декстрин относительно недорогой материал, который широко используется в различных отраслях промышленности. Благодаря наличию в молекуле полярных ковалентных связей различного типа $(\mathrm{O}-\mathrm{H}, \mathrm{C}-\mathrm{H}, \mathrm{C}-\mathrm{O})$ декстрин эффективно поглощает электромагнитное излучение инфракрасного диапазона [24, 25]. Выбор материала для обработки обусловлен тем, что в настоящее время непрерывно возрастает интерес к использованию силуминов в качестве материала для блоков цилиндров и деталей шатуннопоршневой группы бензиновых и дизельных двигателей внутреннего сгорания. По сравне- 
нию с традиционно применяемыми блоками цилиндров из серого чугуна блоки из алюминиевых сплавов имеют ряд преимуществ: наряду с малым удельным весом они обладают высоким удельным модулем упругости, хорошей теплопроводностью, что обеспечивает значительную разгрузку термически нагруженных зон. Вследствие меньшей массы блоков цилиндров и деталей шатунно-поршневой группы снижается потребление горючего и, соответственно, выброс вредных веществ [26]. Однако эти сплавы характеризуются низкой механической прочностью и износостойкостью, которые можно повысить с помощью различных поверхностных обработок. В этой связи, исследование структуры и свойств сплава АК7ч, подвергнутого лазерному упрочнению, является актуальной научной и практической задачей.

\section{2. Материал и методика эксперимента}

Исследовали литейный алюминиевый сплав АК7ч (силумин) по ГОСТ 1583-93 промышленной плавки (табл. 1). Химический состав сплава определяли с использованием оптического эмиссионного спектрометра «SPECTROMAXX F».

Таблица 1 - Химический состав сплава АК7ч

\begin{tabular}{|c|c|c|c|c|c|c|c|c|c|c|c|c|c|}
\hline \multicolumn{10}{|c|}{ Содержание легирующих элементов, мас. \% } \\
\hline \multicolumn{10}{|c|}{ Основных } & \multicolumn{10}{c|}{ Примесей } \\
\hline $\mathrm{Mg}$ & $\mathrm{Si}$ & $\mathrm{Al}$ & $\mathrm{Fe}$ & $\mathrm{Mn}$ & $\mathrm{Cu}$ & $\mathrm{Zn}$ & $\mathrm{Ni}$ & $\mathrm{Ti}+\mathrm{Zr}$ & $\mathrm{Pb}$ & $\mathrm{Sn}$ & $\mathrm{Be}$ & $\mathrm{Bi}$ & $\mathrm{Co}$ \\
\hline 0,32 & 6,34 & Ост. & 0,25 & 0,006 & 0,012 & 0,03 & 0,02 & 0,02 & 0,002 & 0,003 & 0 & 0,012 & 0,009 \\
\hline
\end{tabular}

Составы поглощающих покрытий на основе декстрина представлены в табл. 2. В качестве наполнителей с целью увеличения адгезии покрытия к обрабатываемой поверхности использовали $\mathrm{Na}_{2} \mathrm{O}\left(\mathrm{SiO}_{2}\right)_{\mathrm{n}}$ (натриевое жидкое стекло) и $\mathrm{ZnO}$. Покрытия наносили на поверхность образцов алюминиевого сплава АК7ч путем окрашивания кистью в три тонких слоя с промежуточной сушкой при комнатной температуре в течение 10 мин после нанесения каждого слоя. Перед нанесением покрытий поверхность образцов подвергали механическому шлифованию и обезжиривали ацетоном.

Таблица 2 - Химический состав поглощающих покрытий

\begin{tabular}{|c|c|c|c|}
\hline \multirow{3}{*}{ Покрытие } & \multicolumn{3}{|c|}{ Содержание компонента, об. \% } \\
\cline { 2 - 4 } & $\begin{array}{c}13 \%\left(\mathrm{C}_{6} \mathrm{H}_{10} \mathrm{O}_{5}\right)_{\mathrm{n}}-87 \% \mathrm{H}_{2} \mathrm{O} \\
\text { (водный раствор декстрина) }\end{array}$ & $\begin{array}{c}\mathrm{Na}_{2} \mathrm{O}\left(\mathrm{SiO}_{2}\right)_{\mathrm{n}} \\
\text { (натриевое жидкое стекло) }\end{array}$ & $\mathrm{ZnO}$ \\
\hline 1 & 70 & 30 & - \\
\hline 2 & 70 & - & 30 \\
\hline
\end{tabular}

Лазерную термическую обработку поверхности образцов с нанесенными поглощающими покрытиями с оплавлением поверхности проводили на $\mathrm{CO}_{2}$-лазере Trumpf Lasercell 1005 непрерывного действия с длиной волны излучения $\lambda=10,6$ мкм при мощности излучения $\mathrm{P}=5,0$ кВт и диаметре лазерного пятна на поверхности $\mathrm{d}=7$ мм и оптоволоконном лазере ЛС-10 непрерывного действия с длиной волны излучения $\lambda=1,070$ мкм при мощности излучения $\mathrm{P}=5,0$ кВт и диаметре лазерного пятна на поверхности $\mathrm{d}=6$ мм (рис. 1). Скорость перемещения образца составила $\mathrm{V}=2$ м/мин при обработке с помощью обоих лазеров. В качестве критериев эффективности лазерной обработки использовали следующие характери- 
стики: глубина (h) и ширина (D) зоны оплавления, степень измельчения структуры, микротвердость и шероховатость поверхности.

Микроструктуру сплава до и после лазерной обработки изучали методом оптической микроскопии с применением микроскопа Neophot-21. Микротвердость по методу восстановленного отпечатка определяли на приборе Shimadzu HMV-G21DT при нагрузке 0,245 H, скорости нагружения 40 мкм/с и выдержке под нагрузкой 15 с. Погрешность характеристик микротвердости по 10 измерениям определяли с доверительной вероятностью $\mathrm{p}=0,95$. Распределение элементов по глубине поверхностного слоя изучали методом сканирующей электронной микроскопии (СЭМ) с применением микроскопа Tescan VEGA II XMU с системой рентгеновского энергодисперсионного (ЭДС) микроанализа INCA ENERGY 450. Параметры шероховатости поверхности образцов определяли на участках размером $0,9 \times 1,2$ мм с помощью оптического профилометра Wyko NT-1100.

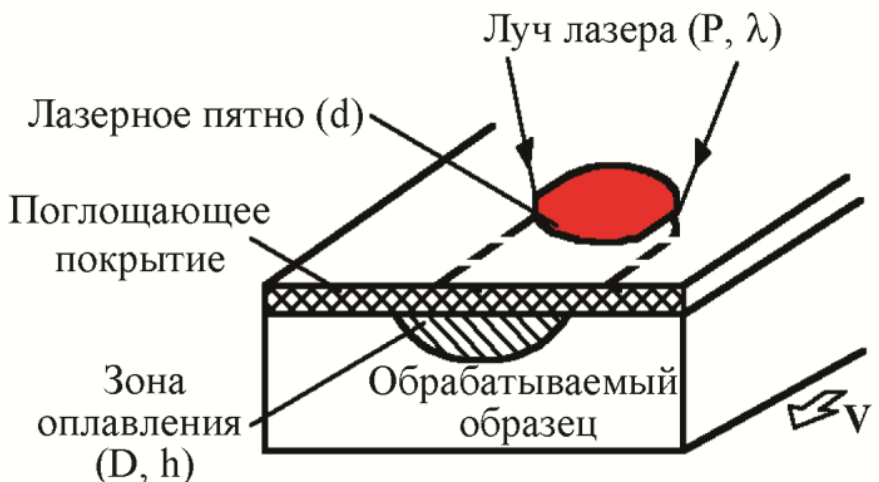

Рис. 1. Схема лазерной термической обработки с оплавлением поверхности:

$\mathrm{P}$ - мощность лазерного излучения; $\lambda$ - длина волны лазерного излучения;

$\mathrm{d}$ - диаметр лазерного пятна на поверхности образца; $\mathrm{V}$ - скорость перемещения образца;

$\mathrm{D}$ - ширина зоны оплавления; $\mathrm{h}$ - глубина зоны оплавления

\section{3. Экспериментальные результаты и их обсуждение}

На рис. 2 приведена микроструктура сплава АК7ч в исходном литом состоянии. Она состоит из дендритов $\alpha$-Al и сетки крупных эвтектических кристаллов кремния по границам дендритных ячеек. Размер дендритных ячеек составляет $\mathrm{d}_{\alpha}=50-190$ мкм, размер кристаллов кремния $\mathrm{d}_{\mathrm{Si}}=5-30$ мкм. В исходном состоянии сплав АК7ч имеет микротвердость $90 \pm 6 \mathrm{HV} 0,025$.

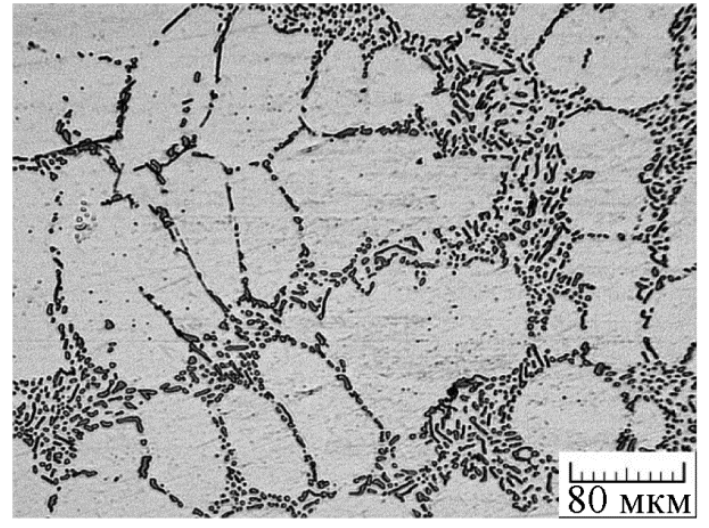

$a$

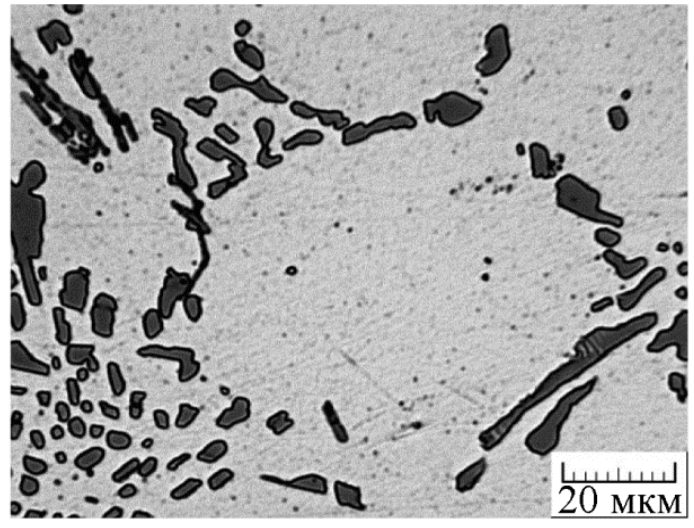

$\sigma$ 
Рис. 2. Микроструктура алюминиевого сплава АК7ч (оптическая микроскопия) в исходном литом состоянии

В табл. 3 и на рис. 3-5 представлены данные о структуре и свойствах поверхностного слоя алюминиевого сплава АК7ч после лазерной термической обработки с использованием двух поглощающих покрытий при обработке лазерным излучением с различной длиной волны. Для всех использованных составов поглощающих покрытий и типов лазеров в результате лазерной обработки на поверхности образцов сплава АК7ч были получены оплавленные слои значительной глубины (табл. 3, рис. 3). При этом глубина и ширина зоны оплавления, полученной с использованием поглощающего покрытия состава 1 больше, чем с использованием поглощающего покрытия состава 2. Эта закономерность сохраняется при обработке лазерным излучением с различной длиной волны. В частности, при обработке с помощью $\mathrm{CO}_{2}$-лазера с использованием поглощающего покрытия состава 1 глубина зоны оплавления составляет $\mathrm{h}=1,16 \mathrm{Mм}$, ширина $\mathrm{D}=8,0 \mathrm{MM}$, а с использованием поглощающего покрытия состава 2 глубина зоны оплавления составляет $\mathrm{h}=0,80$ мм, ширина $\mathrm{D}=5,4$ мм. При обработке с помощью оптоволоконного лазера с использованием поглощающего покрытия состава 1 глубина зоны оплавления составляет $\mathrm{h}=0,75$ мм, ширина $\mathrm{D}=7,0$ мм, а с использованием поглощающего покрытия состава 2 глубина зоны оплавления составляет $\mathrm{h}=0,55$ мм, ширина $\mathrm{D}=5,4$ мм. Полученные результаты свидетельствуют о том, что, во-первых, покрытие состава 1 обладает более высокой поглощающей способностью, чем покрытие состава 2, а вовторых, покрытия обоих составов поглощают излучение $\mathrm{CO}_{2}$-лазера сильнее, чем излучение оптоволоконного лазера. Следует также отметить, что обработка образцов алюминиевого сплава АК7ч с помощью обоих лазеров без использования поглощающих покрытий не приводит к образованию оплавленных слоев на их поверхности.

Таким образом, использование поглощающих покрытий на основе декстрина приводит к образованию на поверхности алюминиевого сплава АК7ч оплавленных слоев значительной глубины (до 1,16 мм), что свидетельствует об их высокой поглощающей способности. При этом в зависимости от состава покрытия глубина зоны оплавления при обработке излучением $\mathrm{CO}_{2}$-лазера с длиной волны $\lambda=10,6$ мкм в 1,45-1,55 раза больше, чем при обработке излучением оптоволоконного лазера с длиной волны $\lambda=1,070$ мкм, т. е. покрытия обоих составов более эффективны при обработке алюминиевого сплава излучением $\mathrm{CO}_{2}$-лазера. Использование поглощающего покрытия состава 1 является более предпочтительным, так как в зависимости от типа лазера обеспечивает глубину зоны оплавления в 1,35-1,45 раза больше, чем поглощающее покрытие состава 2.

Таблица 3 - Глубина $\mathrm{h}$ и ширина $\mathrm{D}$ зоны оплавления, размер дендритных ячеек $\mathrm{d}_{\alpha}$, микротвердость HV 0,025 и шероховатость поверхности Ra в зоне оплавления алюминиевого сплава АК7ч после поверхностной лазерной термической обработки

\begin{tabular}{|c|c|c|c|c|c|c|}
\hline Покрытие & Тип лазера & $\mathrm{h}, \mathrm{mм}$ & $\mathrm{D}, \mathrm{mM}$ & $\mathrm{d}_{\alpha}$, мкм & $\mathrm{HV} 0,025$ & $\mathrm{Ra}$, мкм \\
\hline \multirow{2}{*}{1} & $\mathrm{CO}_{2}$-лазер & 1,16 & 8,0 & $5,0-8,5$ & $110 \pm 6$ & 3,60 \\
\cline { 2 - 7 } & $\begin{array}{c}\text { Оптоволоконный } \\
\text { лазер }\end{array}$ & 0,75 & 7,0 & $5,0-7,0$ & $100 \pm 7$ & 1,03 \\
\hline \multirow{2}{*}{2} & $\mathrm{CO}_{2}$-лазер & 0,80 & 5,4 & $6,5-11,5$ & $105 \pm 5$ & 5,90 \\
\cline { 2 - 7 } & $\begin{array}{c}\text { Оптоволоконный } \\
\text { лазер }\end{array}$ & 0,55 & 5,4 & $5,5-8,0$ & $100 \pm 3$ & 3,90 \\
\hline
\end{tabular}

В результате лазерной термической обработки происходит существенное измельчение структуры сплава АК7ч в зоне оплавления (табл. 3, рис. 3 и 4). При этом состав 
поглощающего покрытия и тип лазера не оказывают существенного влияния на степень дисперсности структуры сплава АК7ч после лазерной обработки. В частности, размер дендритных ячеек составляет $\mathrm{d}_{\alpha}=5,0-11,5$ мкм, а размер эвтектических кристаллов кремния по границам дендритных ячеек $\mathrm{d}_{\mathrm{Si}}=0,5-2,0$ мкм, что на порядок меньше, чем в исходном литом состоянии $\left(\mathrm{d}_{\alpha}=50-190\right.$ мкм, $\mathrm{d}_{\mathrm{Si}}=5-30$ мкм). Кристаллы кремния имеют округлую форму, что обусловлено их растворением в процессе лазерной обработки и последующей кристаллизацией с высокой скоростью при остывании поверхностного слоя. Подобное изменение микроструктуры наблюдали в сплаве АЛ4 (АК9ч) после лазерной обработки которого с помощью $\mathrm{CO}_{2}$-лазера размер дендритных ячеек в зоне оплавления составил 5-8 мкм [27], а в сплаве АЛ26 в результате лазерной обработки наблюдали уменьшение размера первичных кристаллов кремния в 18-40 раз, причем они имели форму, близкую к глобулярной [22].

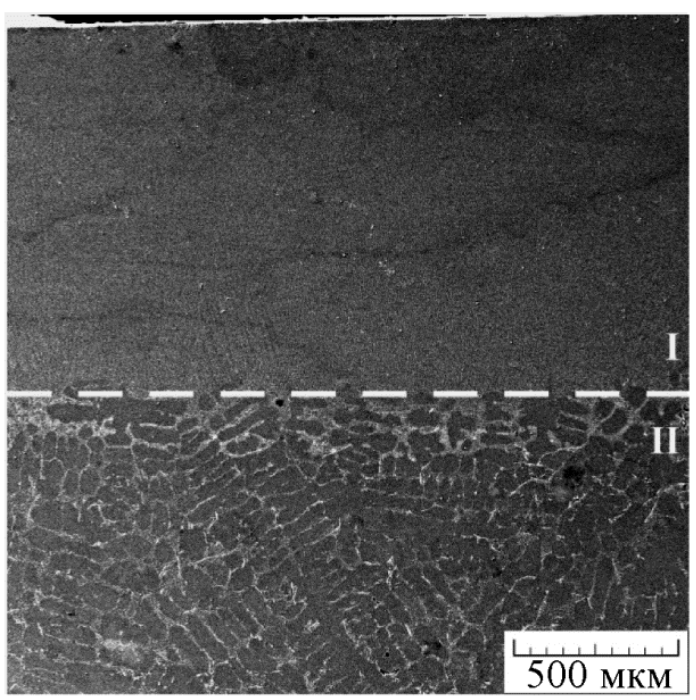

$a$

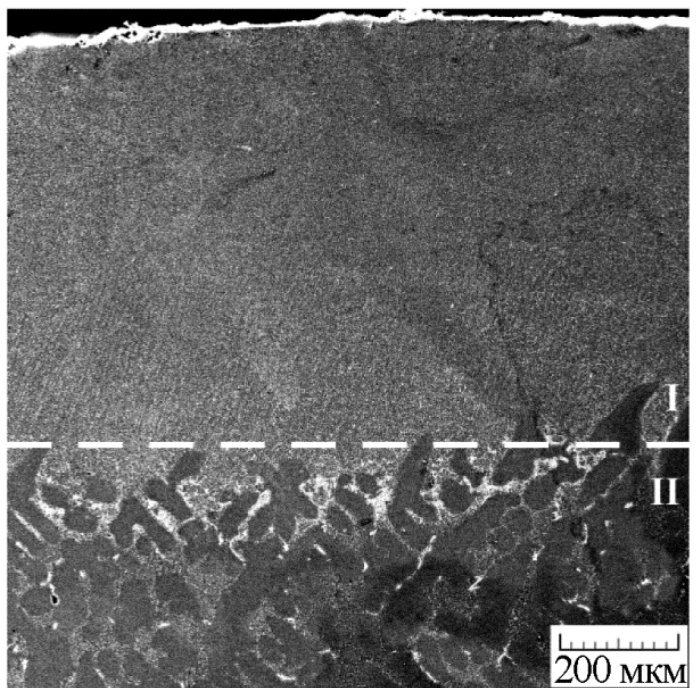

B

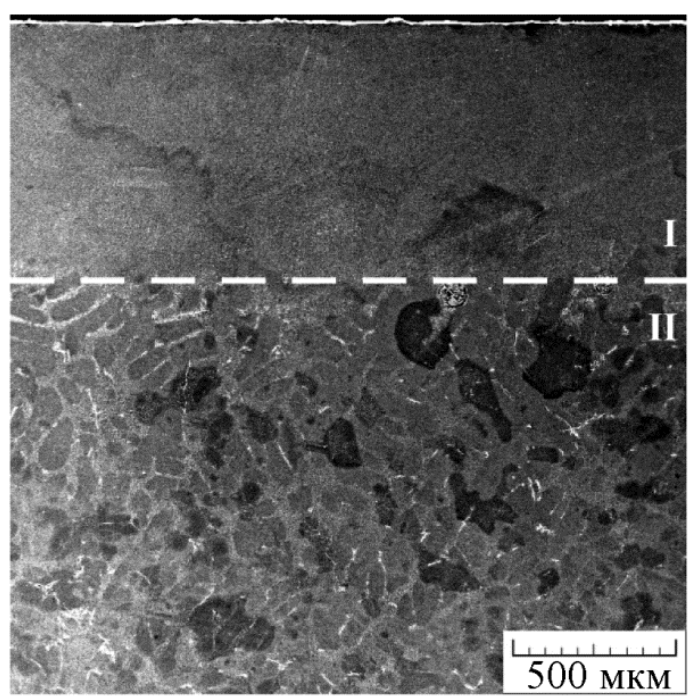

$\sigma$

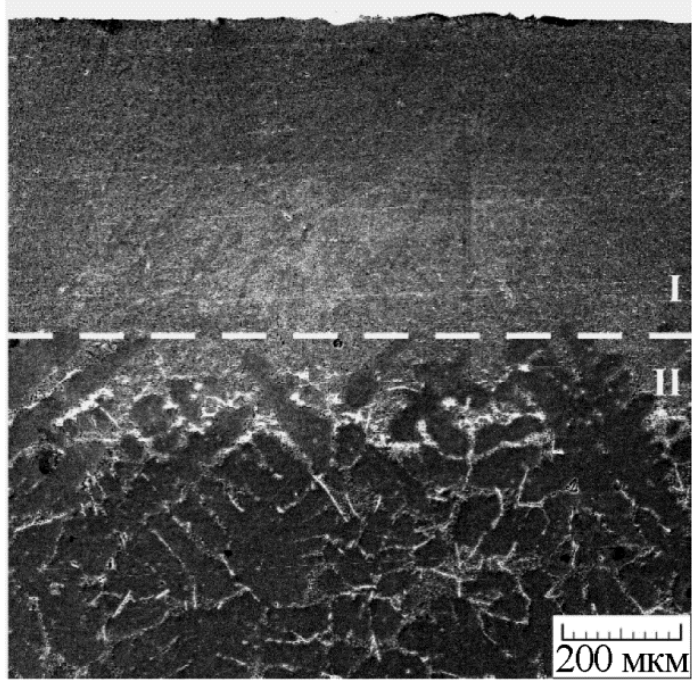

2

Рис. 3. Структура поверхностного слоя алюминиевого сплава АК7ч (электронная сканирующая микроскопия) после поверхностной лазерной термической обработки с использованием поглощающих покрытий составов $1(a, \sigma)$ 
и $2\left(6\right.$, г) при обработке с помощью $\mathrm{CO}_{2}$-лазера $(\mathrm{a}, \mathrm{в})$ и оптоволоконного лазера $(6$, г).

$I$ - зона оплавления, $I I$ - основной металл.

Лазерная термическая обработка также приводит к некоторому упрочнению поверхности алюминиевого сплава АК7ч (табл. 3). При этом состав поглощающего покрытия и тип лазера не оказывают существенного влияния на микротвердость сплава АК7ч после лазерной обработки. В частности, микротвердость поверхности сплава АК7ч возрастает от 90 до 100-110 HV 0,025, что обусловлено наблюдаемым измельчением структуры сплава АК7ч в зоне оплавления (табл. 3, рис. 3 и 4). Результаты измерения микротвердости на различной глубине также свидетельствуют о том, что более высокая твердость сплава АК7ч в зоне оплавления сохраняется вплоть до границы с основным металлом (рис. 5).

Таким образом, использование поглощающих покрытий на основе декстрина приводит к существенному измельчению структуры и некоторому упрочнению сплава АК7ч в зоне оплавления. При этом размер дендритных ячеек $\alpha$-Al уменьшается от 50-190 мкм до 5,0-11,5 мкм, размер кристаллов кремния уменьшается от 5-30 мкм до 0,5-2,0 мкм, а микротвердость возрастает в 1,11-1,22 раза по сравнению со значением микротвердости сплава в исходном литом состоянии (90 HV 0,025). Состав поглощающего покрытия не оказывает существенного влияния на структуру и микротвердость сплава АК7ч после лазерной обработки.

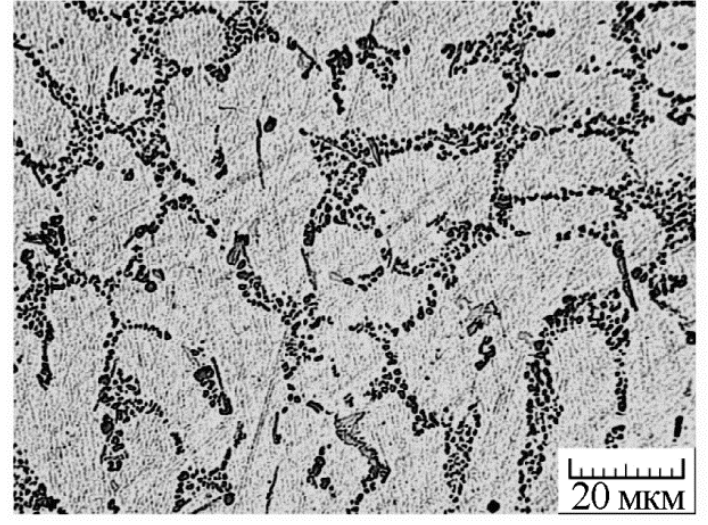

$a$

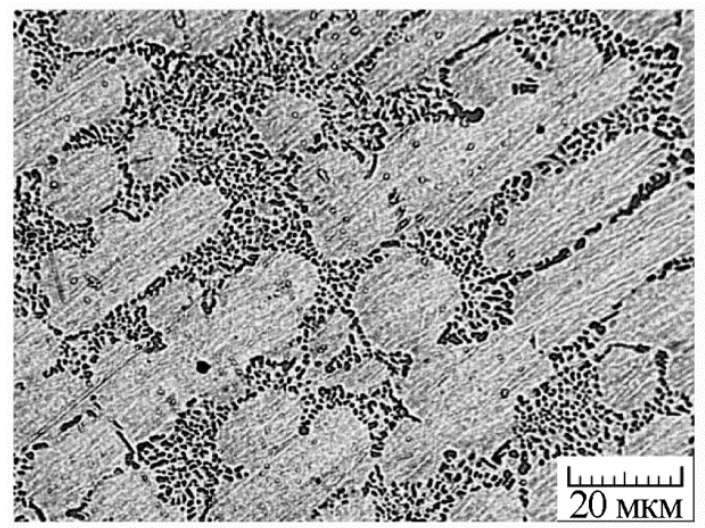

6

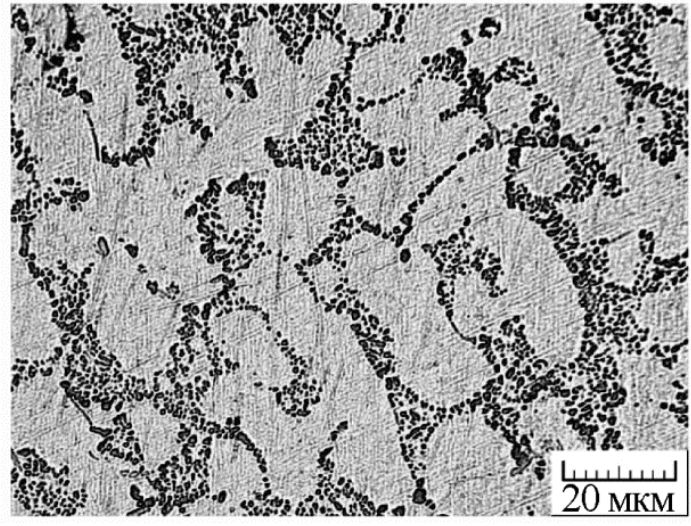

$\sigma$

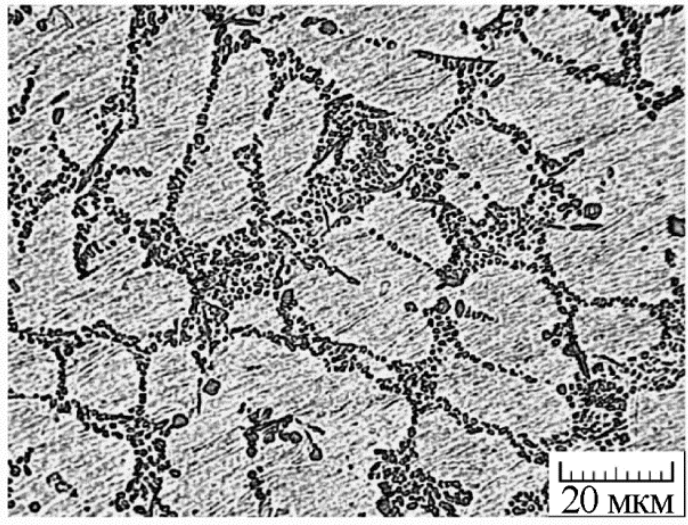

2

Рис. 4. Микроструктура алюминиевого сплава АК7ч в зоне оплавления (оптическая микроскопия) после поверхностной лазерной термической обработки с использованием поглощающих покрытий составов $1(a, \sigma)$ и $2(b, 2)$ при обработке с помощью $\mathrm{CO}_{2}$-лазера $(a, b)$ и оптоволоконного лазера $(\sigma, 2)$ 


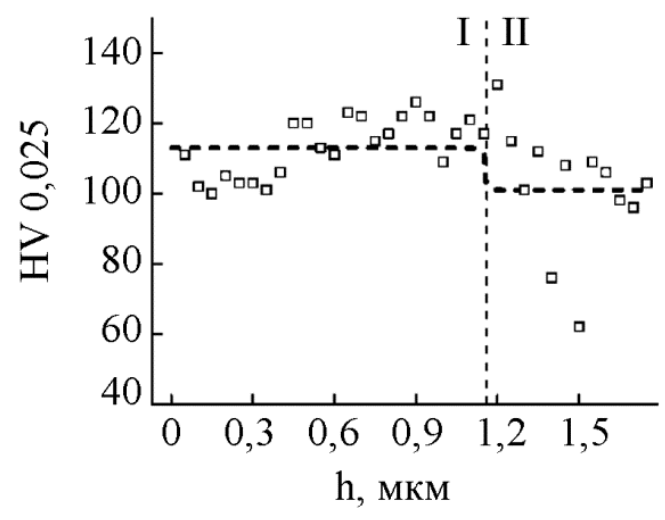

$a$

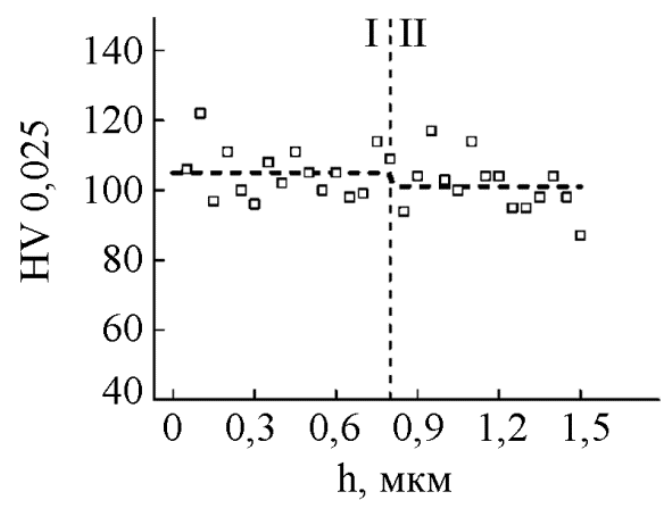

B

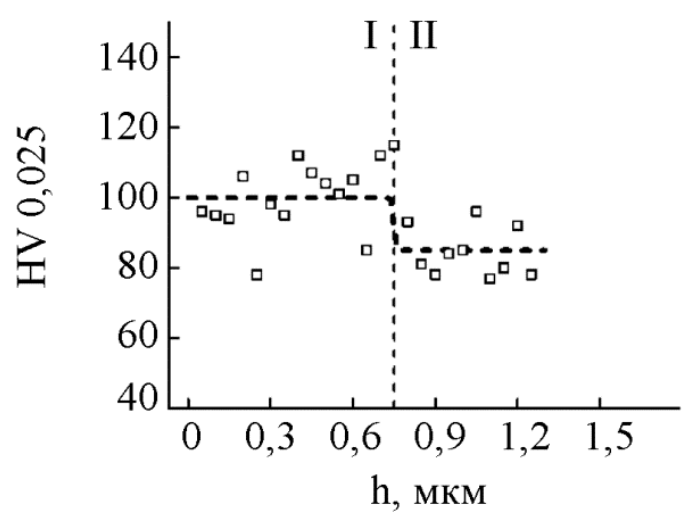

$\sigma$

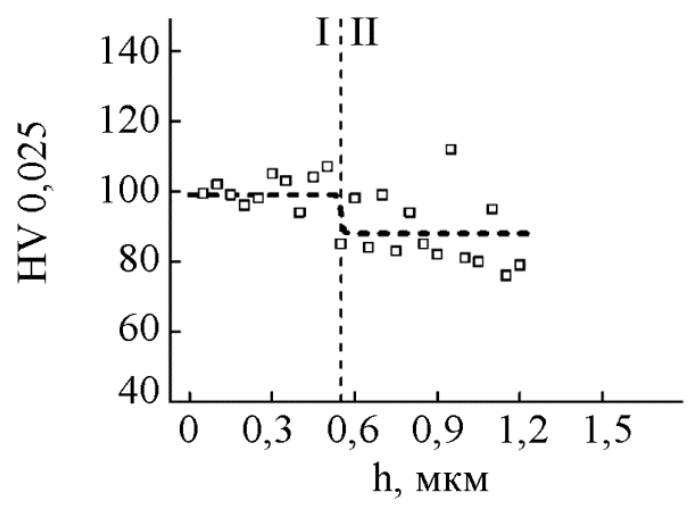

2

Рис. 5. Микротвердость HV 0,025 в поверхностном слое алюминиевого сплава АК7ч на различной глубине $\mathrm{h}$ после поверхностной лазерной термической обработки с использованием поглощающих покрытий составов $1(a, \sigma)$ и $2(6,2)$ при обработке с помощью $\mathrm{CO}_{2}$-лазера $(a, b)$ и оптоволоконного лазера $(\sigma, z)$. $I-$ зона оплавления, $I I-$ основной металл

В табл. 3 и на рис. 6 и 7 представлены результаты измерения шероховатости и рельефа поверхности алюминиевого сплава АК7ч после лазерной термической обработки. В частности, при обработке с помощью $\mathrm{CO}_{2}$-лазера, с использованием поглощающего покрытия составов 1 и 2, шероховатость поверхности Ra зоны оплавления составляет 3,60 и 5,90 мкм соответственно, а при обработке с помощью оптоволоконного лазера - 1,03 и 3,90 мкм. При этом в зависимости от состава покрытия шероховатость поверхности $\mathrm{Ra}$ зоны оплавления при обработке с помощью $\mathrm{CO}_{2}$-лазера несколько больше, чем при обработке с помощью оптоволоконного лазера. Это может быть обусловлено тем, что увеличение глубины проплавления, наблюдаемое при обработке с помощью $\mathrm{CO}_{2}$-лазера, согласно уравнению теплопроводности снижает подвод теплоты к фронту фазового перехода и уменьшает скорость его перемещения. В свою очередь это приводит к перегреву поверхностных слоев расплава, что способствует усилению конвективных потоков в расплаве [28]. Соответственно более интенсивные колебания расплава приводят к большей шероховатости поверхности алюминиевого сплава АК7ч после лазерной обработки. 


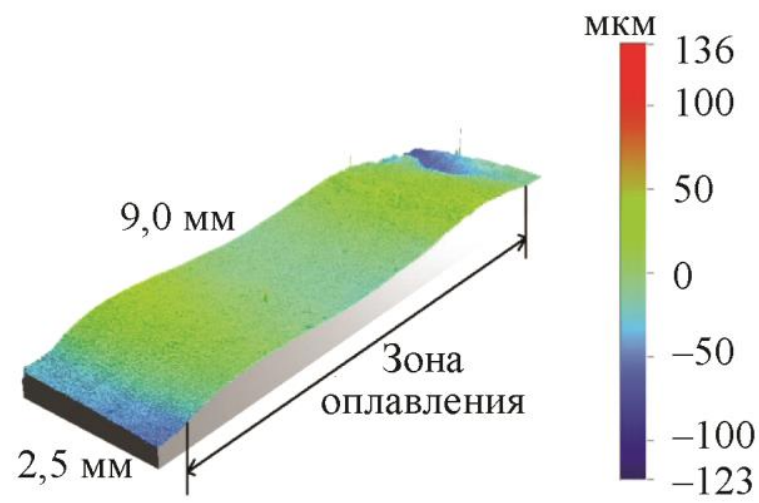

$a$

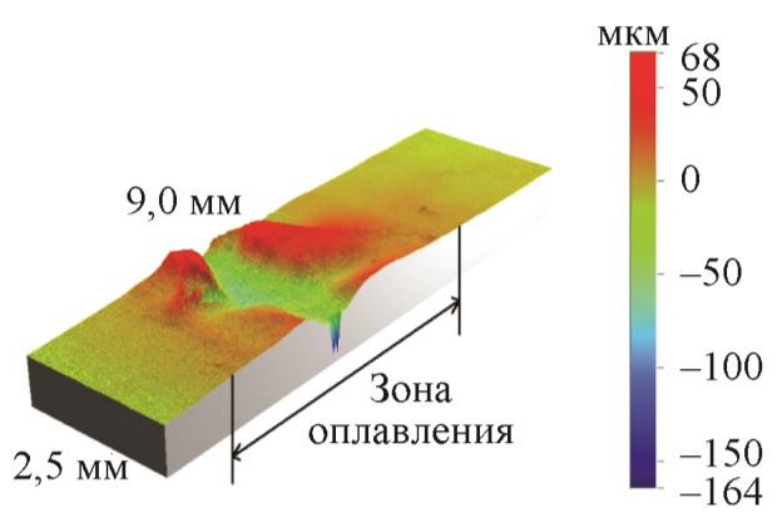

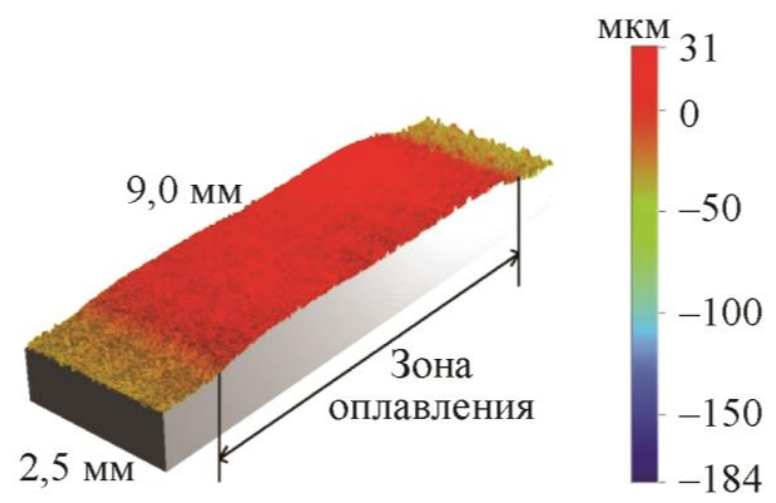

$\sigma$

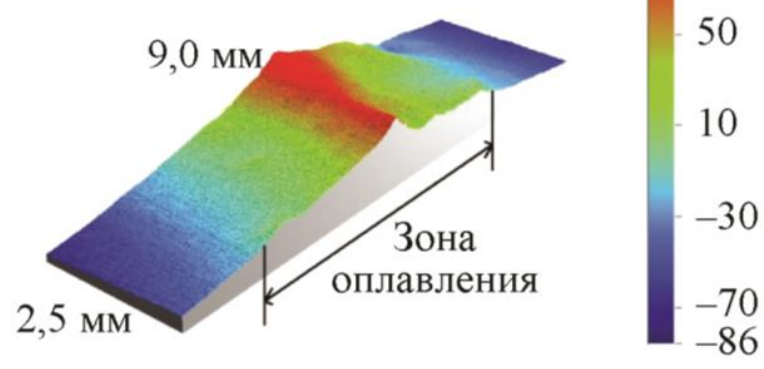

2

Рис. 6. Вид поверхности алюминиевого сплава АК7ч (оптическая профилометрия) после поверхностной лазерной термической обработки с использованием поглощающих покрытий составов $1(a, \sigma)$ и $2(b, z)$ при обработке с помощью $\mathrm{CO}_{2}$-лазера $(a, b)$ и оптоволоконного лазера $(6,2)$

Основной причиной и движущей силой конвекции являются градиенты поверхностного натяжения и капиллярные силы. При лазерном нагреве в центре пучка температура тела максимальна и спадает к краям. Поверхностное натяжение жидкости (расплава) у зависит от температуры Т и обычно уменьшается с ее ростом. Вследствие этого на поверхности возникает сила, направленная от центра светового пятна к его краям, и возникает движение жидкости [22]. После прекращения действия лазерного излучения поток тепла от расплава осуществляется через границу «жидкость - твердое тело», по механизму теплопроводности; с другой стороны, теплоотвод с поверхности раздела «газ - жидкость» является затрудненным (из-за низкой теплопроводности окружающего газа), поэтому поверхность ванны расплава остается еще жидкой, когда объем ванны уже затвердел, и из-за наличия начального импульса, возникшего в момент воздействия лазерного излучения, и ряда других факторов, колеблется после прекращения воздействия лазерного излучения вплоть до момента кристаллизации [29]. 

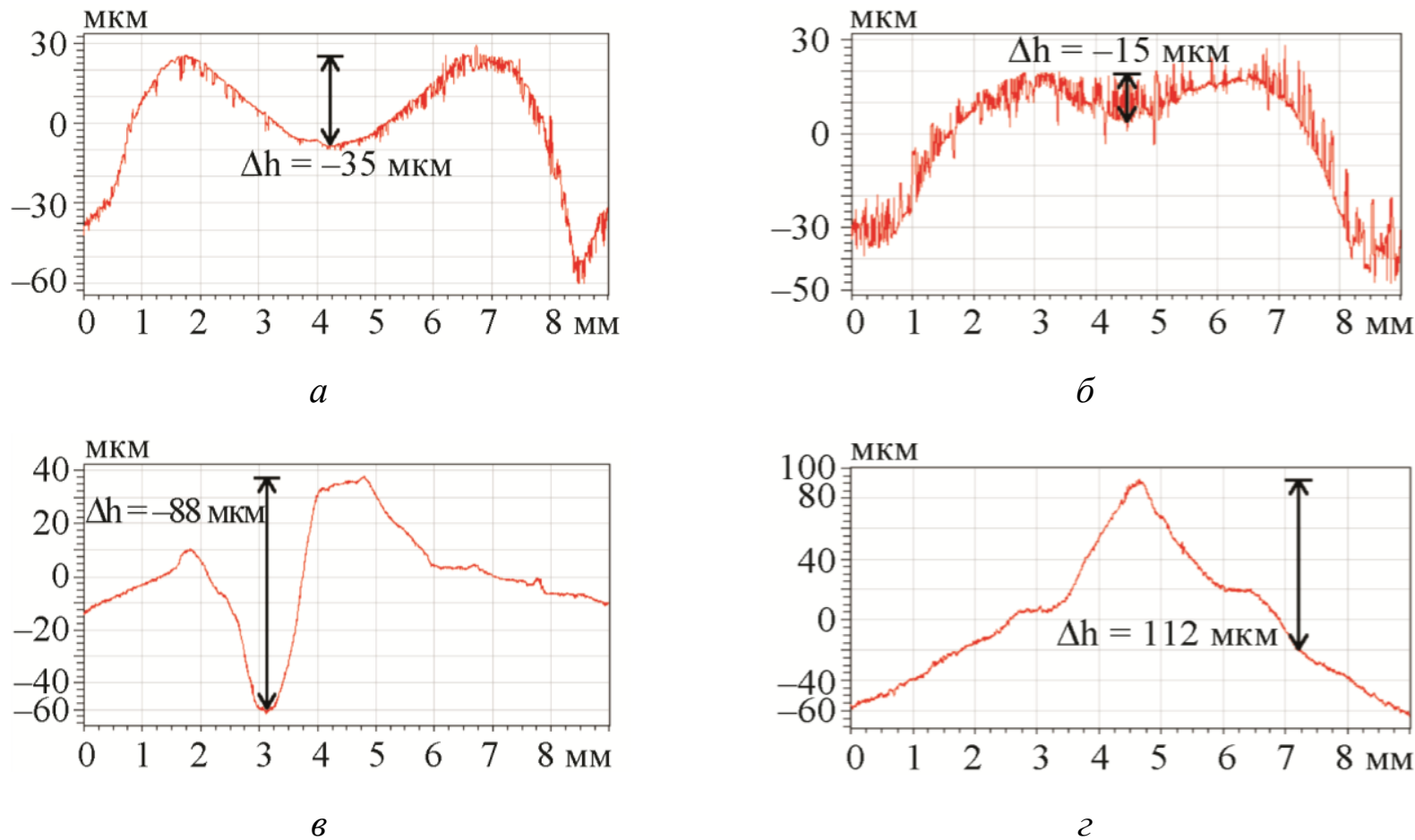

Рис. 7. Профиль сечения вдоль ширины зоны оплавления алюминиевого сплава АК7ч (оптическая профилометрия) после поверхностной лазерной термической обработки с использованием поглощающих покрытий составов $1(a, \sigma)$ и $2(8$, г) при обработке с помощью $\mathrm{CO}_{2}$-лазера $(a, b)$ и оптоволоконного лазера $(6,2)$

Из табл. 3 также следует, что при обработке лазерным излучением с различной длиной волны шероховатость поверхности Ra зоны оплавления, полученной с использованием поглощающего покрытия состава 2 больше, чем с использованием поглощающего покрытия состава 1. Кроме того, использование поглощающего покрытия состава 2, приводит к формированию глубокой впадины (рис. 6 в, 7 в) или выброса застывшего металла (рис. 6 г, 7 г) в центре зоны оплавления, тогда как при обработке с использованием поглощающего покрытия состава 1 поверхность образца в зоне оплавления более ровная с небольшим углублением между центром зоны и ее периферией (рис. $6 a, 6,7 a, \sigma)$. Известно, что форма поверхности ванны расплава (вогнутая, выпуклая), направление конвективных потоков на поверхности (к краям или к центру жидкой ванны), отношение размеров (глубина/ширина) сечения лазерной дорожки и другие параметры зависят от значения и знака производной $\partial \sigma / \partial \mathrm{T}$ (рис. 8). Для чистых веществ тепловая зависимость коэффициента поверхностного натяжения $\partial \sigma / \partial \mathrm{T}$ всегда меньше нуля (рис. 8 a), однако наличие даже микропримесей как поверхностно-активных веществ, так и поверхностно-инактивных веществ, может привести к смене знака производной $\partial \sigma / \partial \mathrm{T}$ (рис. 8 б) и кардинально изменить характер конвекции при лазерной обработке [22]. Исследование химического состава поверхностного слоя алюминиевого сплава АК7ч после обработки с помощью оптоволоконного лазера с использованием поглощающего покрытия состава 2 показало повышенное содержание цинка (до 0,2 мас. \%) и кислорода (до 1,25 мас. \%) в зоне оплавления в слое толщиной до 45 мкм по сравнению с содержанием в более глубоких слоях и в основном металле (рис. 9). Это свидетельствует о частичном разрушении поглощающего покрытия состава 2 при лазерной обработке с помощью оптоволоконного лазера и попадании частиц оксида цинка $\mathrm{ZnO}$ из поглощающего покрытия в расплав, что, по-видимому, является причиной изменения конвекционных потоков в расплаве и формирования выпуклой формы зоны оплавления (рис. 6 2, 7 2). Полученные резуль- 
таты свидетельствуют о том, что поглощающее покрытие состава 2 характеризуется термической нестабильностью в данных условиях нагрева. Следует отметить, что наблюдаемое повышенное содержание цинка и кислорода не влияет на микротвердость сплава АК7ч после лазерной обработки (табл. 3).
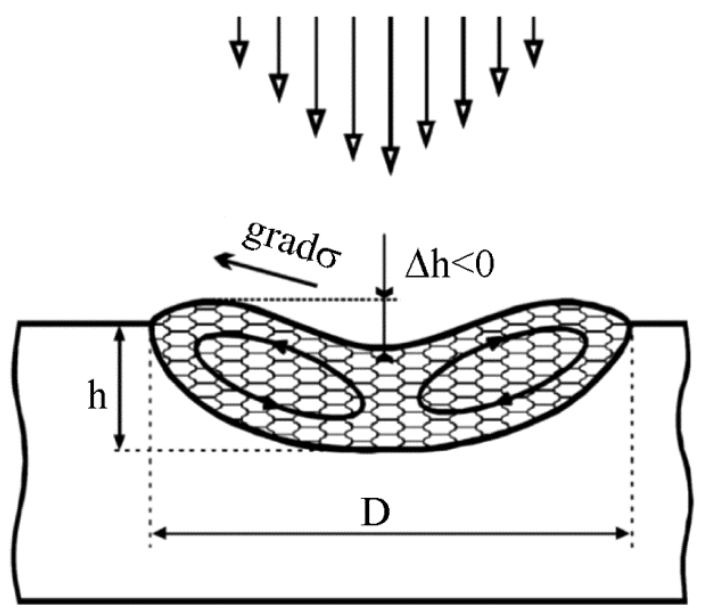

$a$
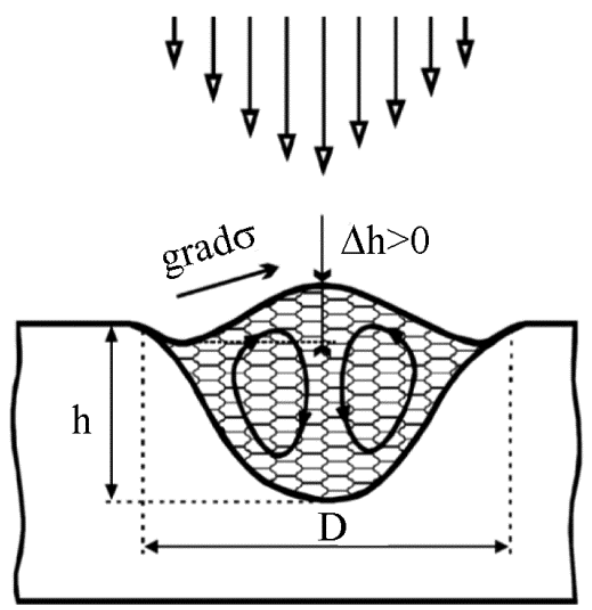

$\sigma$

Рис. 8. Характер перемешивания жидкости в ванне расплава при $\partial \sigma / \partial \mathrm{T}<0(a)$ и $\partial \sigma / \partial \mathrm{T}>0$ (б). $\Delta \mathrm{h}$ - величина деформации поверхности; $\sigma$ - поверхностное натяжение расплава; T - температура; D - ширина зоны оплавления; $\mathrm{h}$ - глубина зоны оплавления [22]

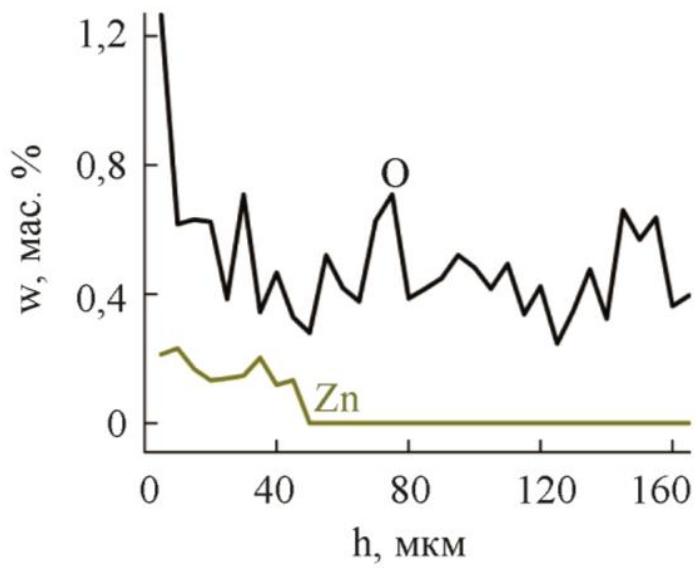

Рис. 9. Массовые доли элементов w в поверхностном слое алюминиевого сплава АК7ч на различной глубине h (энергодисперсионный микроанализ) после поверхностной лазерной термической обработки с использованием поглощающего покрытия состава 2 при обработке с помощью оптоволоконного лазера

Величина деформации поверхности при лазерном плавлении $\Delta \mathrm{h}$ пропорциональна производной $\partial \sigma / \partial \mathrm{T}$ и увеличивается с ростом разности температур поверхности жидкости на границе и в центре зоны оплавления [22]. Из рис. 7 видно, что при лазерной обработке алюминиевого сплава АК7ч с использованием поглощающего покрытия состава 2 величина $\Delta \mathrm{h}$ больше, чем с использованием поглощающего покрытия состава 1 . Это свидетельствует о менее равномерном нагреве поверхности сплава в процессе обработки с использованием данного покрытия, обусловленном его термической нестабильностью. Неравномерный нагрев может являться причиной большей шероховатости поверхности, а также меньшей 
глубины и ширины зоны оплавления, полученной с использованием поглощающего покрытия состава 2, по сравнению с размерами зоны оплавления, полученной с использованием поглощающего покрытия состава 1 (табл. 3 ; рис. 3 ).

На рис. 10 и11 представлены данные о распределении элементов в поверхностном слое алюминиевого сплава АК7ч после лазерной термической обработки с использованием двух поглощающих покрытий при обработке с помощью $\mathrm{CO}_{2}$-лазера. Видно, что по сравнению с основным металлом зона оплавления характеризуется более равномерным распределением легирующих элементов, обусловленным ее дисперсной структурой (табл. 3; рис. 3 и 4). Это свидетельствует о хорошем перемешивании расплава при лазерной обработке. Согласно оценкам [22], за время существования жидкой ванны расплава жидкость в ней успевает совершить несколько сотен оборотов, т. е. перемешивание является полным.

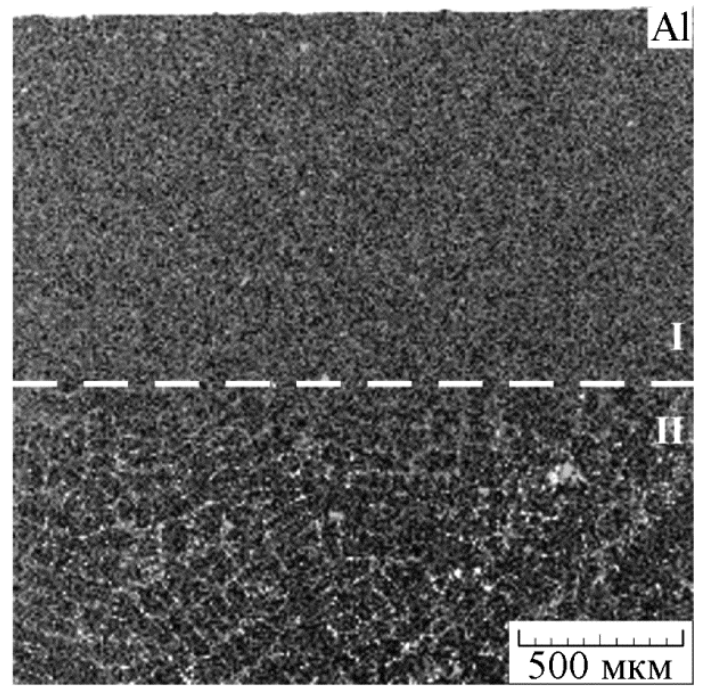

$a$

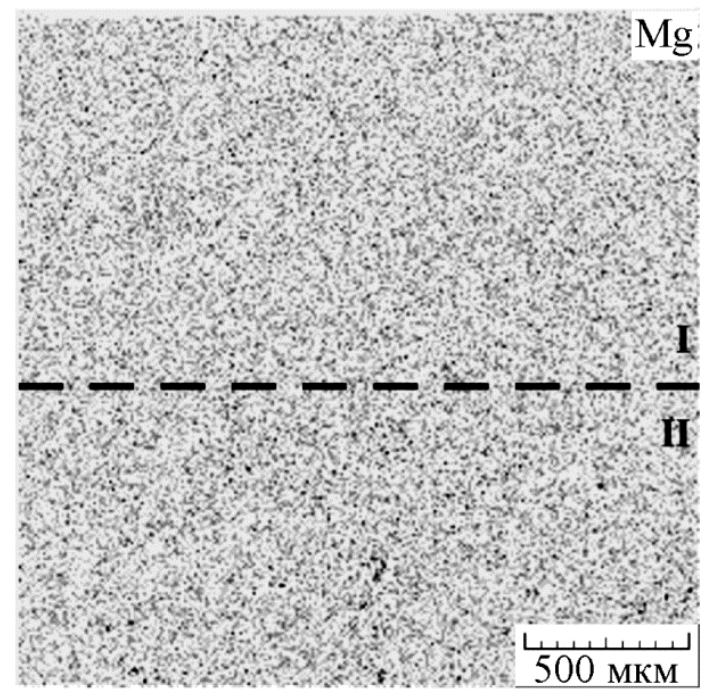

B

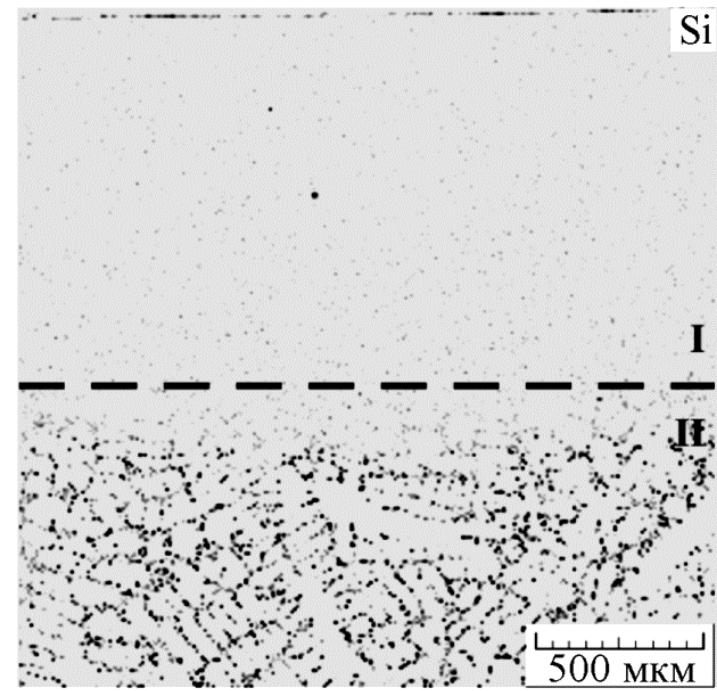

6

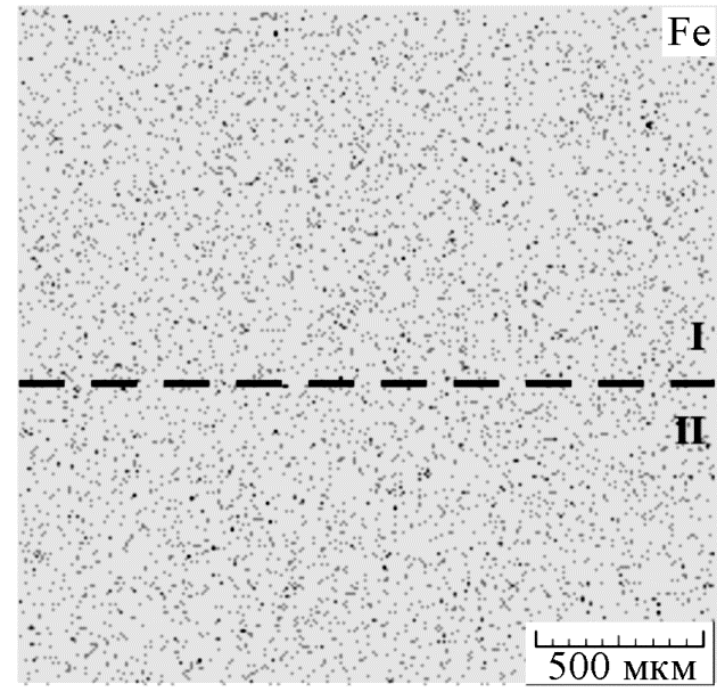

2

Рис. 10. Карты элементов в поверхностном слое алюминиевого сплава АК7ч (энергодисперсионный микроанализ) после поверхностной лазерной термической обработки с использованием поглощающего покрытия состава 1 при обработке с помощью $\mathrm{CO}_{2}$-лазера. $I$ - зона оплавления; $I I-$ основной металл 


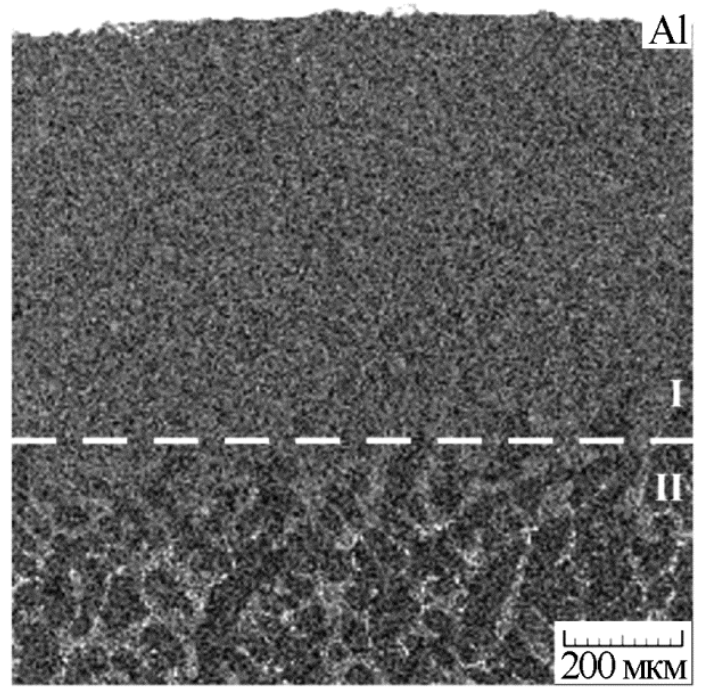

$a$

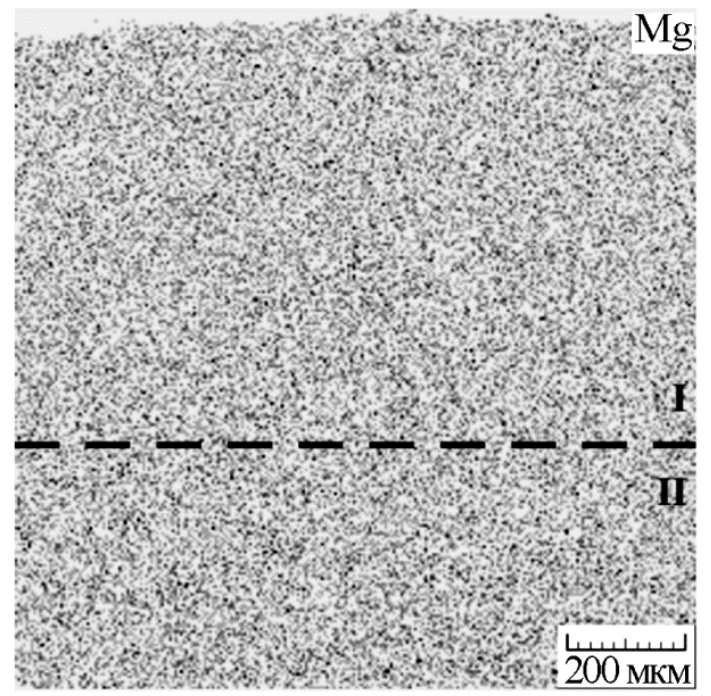

B

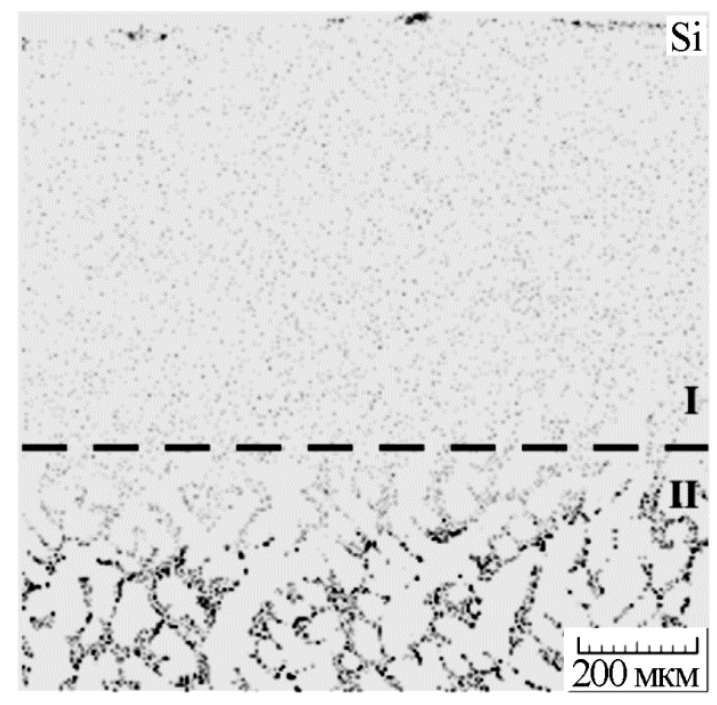

$\sigma$

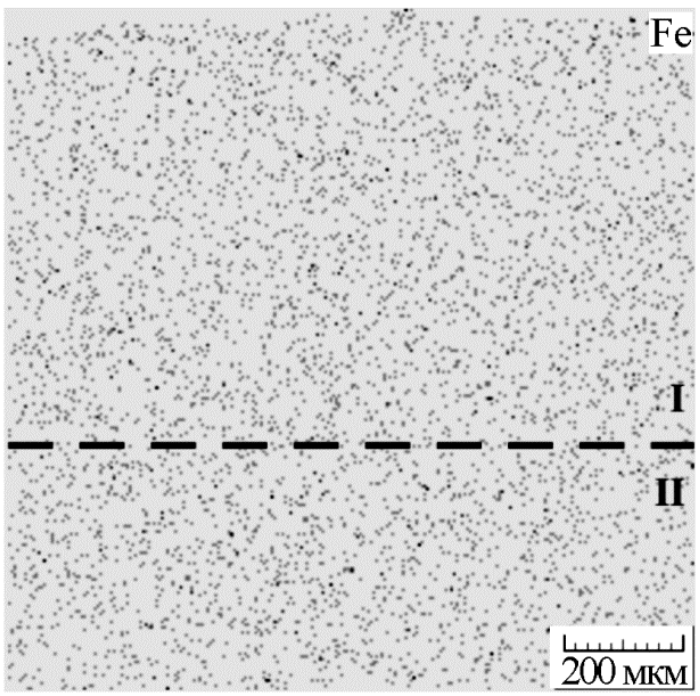

2

Рис. 11. Карты элементов в поверхностном слое алюминиевого сплава АК7ч (энергодисперсионный микроанализ) после поверхностной лазерной термической обработки с использованием поглощающего покрытия состава 2 при обработке с помощью $\mathrm{CO}_{2}$-лазера. $I$ - зона оплавления; $I I-$ основной металл

Таким образом, в зависимости от состава покрытия шероховатость поверхности Ra зоны оплавления при обработке с помощью $\mathrm{CO}_{2}$-лазера в 1,5-3,5 раза выше, чем при обработке с помощью оптоволоконного лазера, что обусловлено более интенсивными колебаниями расплава вследствие увеличения глубины проплавления при обработке с помощью $\mathrm{CO}_{2}-$ лазера. В зависимости от типа лазера шероховатость поверхности Ra зоны оплавления, полученной с использованием поглощающего покрытия состава 2, в 1,6-3,8 раза больше, чем с использованием поглощающего покрытия состава 1 . Это также обусловлено усилением интенсивности колебаний расплава вследствие более неравномерного нагрева поверхности сплава в процессе обработки с использованием покрытия состава 2. Такое поведение поглощающего покрытия состава 2 может быть вызвано его термической нестабильностью, о чем свидетельствует частичное разрушение покрытия при лазерной обработке с помощью оптоволоконного лазера, приводящее к повышенному содержание цинка (до 0,2 мас. \%) и кисло- 
рода (до 1,25 мас. \%) в зоне оплавления в слое толщиной до 45 мкм. При этом использование поглощающих покрытий обоих составов обеспечивает равномерное распределение легирующих элементов в зоне оплавления, что свидетельствует о хорошем перемешивании расплава при лазерной обработке. Для обеспечения наилучшего качества поверхности и наибольшей глубины зоны оплавления, лазерную обработку алюминиевого сплава АК7ч целесообразно проводить с использованием поглощающего покрытия состава 1 с помощью как $\mathrm{CO}_{2}-$ лазера, так и оптоволоконного лазера.

\section{4. Заключение}

Исследована микроструктура, микротвердость, шероховатость поверхности и химический состав литейного алюминиевого сплава АК7ч после поверхностной лазерной термической обработки с использованием новых поглощающих покрытий на основе декстрина составов 1 (водный раствор декстрина $+\mathrm{Na}_{2} \mathrm{O}\left(\mathrm{SiO}_{2}\right)_{\mathrm{n}}$ ) и 2 (водный раствор декстрина $+\mathrm{ZnO}$ ). Обработку проводили на $\mathrm{CO}_{2}$-лазере с длиной волны излучения 10,6 мкм и оптоволоконном лазере с длиной волны излучения 1,070 мкм.

Установлено, что использование поглощающих покрытий на основе декстрина приводит к образованию на поверхности алюминиевого сплава АК7ч оплавленных слоев значительной глубины, что свидетельствует об их высокой поглощающей способности. В частности, при обработке с помощью $\mathrm{CO}_{2}$-лазера с использованием поглощающего покрытия составов 1 и 2 глубина зоны оплавления составляет соответственно 1,16 и 0,80 мм, а при обработке с помощью оптоволоконного лазера, соответственно, 0,75 и 0,55 мм. При этом в зависимости от состава покрытия глубина зоны оплавления при обработке излучением $\mathrm{CO}_{2}$ лазера в 1,45-1,55 раза больше, чем при обработке излучением оптоволоконного лазера, т. е. покрытия обоих составов более эффективны при обработке алюминиевого сплава излучением $\mathrm{CO}_{2}$-лазера. Использование поглощающего покрытия состава 1 является более предпочтительным, так как в зависимости от типа лазера обеспечивает глубину зоны оплавления в 1,35-1,45 раза больше, чем поглощающее покрытие состава 2.

В результате лазерной термической обработки с использованием поглощающих покрытий обоих составов происходит существенное измельчение структуры и некоторое упрочнение сплава АК7ч в зоне оплавления. При этом размер дендритных ячеек б-Аl уменьшается от 50-190 мкм до 5,0-11,5 мкм, размер кристаллов кремния уменьшается от 5-30 мкм до 0,5-2,0 мкм, а микротвердость возрастает в 1,11-1,22 раза по сравнению со значением микротвердости сплава в исходном литом состоянии (90 HV0,025). Состав поглощающего покрытия не оказывает существенного влияния на структуру и микротвердость сплава АК7ч после лазерной обработки.

Исследование рельефа поверхности показало, что при обработке с помощью $\mathrm{CO}_{2}$ лазера с использованием поглощающего покрытия составов 1 и 2, шероховатость поверхности $\mathrm{Ra}$ зоны оплавления составляет соответственно 3,60 и 5,90 мкм, а при обработке с помощью оптоволоконного лазера 1,03 и 3,90 мкм. При этом в зависимости от состава покрытия шероховатость поверхности $\mathrm{Ra}$ зоны оплавления при обработке с помощью $\mathrm{CO}_{2}$-лазера в 1,5-3,5 раза выше, чем при обработке с помощью оптоволоконного лазера, что обусловлено более интенсивными колебаниями расплава вследствие увеличения глубины проплавления при обработке с помощью $\mathrm{CO}_{2}$-лазера. В зависимости от типа лазера шероховатость поверхности Ra зоны оплавления, полученной с использованием поглощающего покрытия состава 2, в 1,6-3,8 раза больше, чем с использованием поглощающего покрытия состава 1. Это также обусловлено усилением интенсивности колебаний расплава вследствие менее равномерного нагрева поверхности сплава в процессе обработки с использованием покрытия состава 2. Такое поведение поглощающего покрытия состава 2 может быть вызвано его термической нестабильностью, о чем свидетельствует частичное разрушение покрытия при лазерной обработке с помощью оптоволоконного лазера, приводящее к повышенному содержанию цин- 
ка (до 0,2 мас. \%) и кислорода (до 1,25 мас. \%) в зоне оплавления в слое толщиной до 45 мкм. При этом использование поглощающих покрытий обоих составов обеспечивает равномерное распределение легирующих элементов в зоне оплавления, что свидетельствует о хорошем перемешивании расплава при лазерной обработке.

Таким образом, для обеспечения наилучшего качества поверхности и наибольшей глубины зоны оплавления, лазерную обработку алюминиевого сплава АК7ч целесообразно проводить с использованием поглощающего покрытия состава 1 с помощью как $\mathrm{CO}_{2}$-лазера, так и оптоволоконного лазера.

\section{Благодарность}

Работа выполнена в рамках Комплексной программы УрО РАН (проект № 18-10-140) и в рамках государственного задания ФАНО России по теме «Структура» № АAAA-A18118020190116-6.

Электронная сканирующая и оптическая микроскопия, оптическая профилометрия и микродюрометрия выполнены в ЦКП «Пластометрия» ИМАШ УрО РАН.

Авторы выражают благодарность Л.А. Одинияовой за участие в разработке составов поглощающих покрытий и проведение обработки образиов на оптоволоконном лазере.

\section{Литература}

1. On the possibility of increasing the service life of high-power laser optics through the use of polycrystalline diamond windows with a central monocrystalline area / M. V. Rogozhin, V. E. Rogalin, M. I. Krymskii, I. A. Kaplunov // Diagnostics, Resource and Mechanics of materials and structures. - 2018. - Iss. 1. - P. 34-40. - URL: http://dream-journal.org/issues/2018-1/20181_132.html

2. Влияние лазерной обработки на структуру, износостойкость и усталостные свойства высокопрочного чугуна / А. В. Макаров, И. Ю. Малыгина, А. Л. Осинцева // Физика и химия обработки материалов. - 2006. - № 4. - С. 46-55.

3. Pugacheva N. B., Michurov N. S., Trushina E. B. Peculiarities of the structure of welded aluminum alloy joints // Diagnostics, Resource and Mechanics of materials and structures. - 2015. Iss. 5. - P. 58-71. - URL: http://dream-journal.org/issues/2015-5/2015-5_43.html

4. Макаров А. В., Соболева Н. Н. Формирование износостойких NiCrBSi покрытий лазерной наплавкой и комбинированными обработками // Перспективные материалы. Т. VII : учебное пособие / под ред. Д. Л. Мерсона. - Тольятти : ТГУ, 2017. - 292 с. Глава 5. - С. 167-238.

5. Формирование износостойкого хромоникелевого покрытия с особо высоким уровнем теплостойкости комбинированной лазерно-термической обработкой / А. В. Макаров, Н. Н. Соболева, И. Ю. Малыгина, А. Л. Осинцева // Металловедение и термическая обработка металлов. - 2015. - № 3. - С. 39-46.

6. Влияние химического состава на трибологические свойства хромоникелевых покрытий, полученных методом газопорошковой лазерной наплавки / А. В. Макаров, Р. А. Саврай, А. Л. Осинцева, И. Ю. Малыгина // Известия Челябинского научного центра УрО РАН. 2009. - № 2 (44). - C. 28-33.

7. Eddy-current testing of the hardness, wear resistance, and thickness of coatings prepared by gas-powder laser cladding / A. V. Makarov, E. S. Gorkunov, I. Yu. Malygina, L. Kh. Kogan, R. A. Savrai, A. L. Osintseva // Russian Journal of Nondestructive Testing. - 2009. - Vol. 45, iss. 11. - P. 797-805. - DOI: 10.1134/S1061830909110060.

8. Влияние микроструктуры и фазового состава на трибологические свойства $\mathrm{NiCrBSi}$ лазерных покрытий / Н. Н. Соболева, И. Ю. Малыгина, А. Л. Осинцева, Н. А. Поздеева // Известия Самарского научного центра РАН. - 2011. - Т. 13, № 4 (3). - С. 869-873. 
9. Макаров А.В., Соболева Н.Н., Малыгина И.Ю. Роль упрочняющих фаз в сопротивлении абразивному изнашиванию $\mathrm{NiCrBSi}$ покрытий, сформированных лазерной наплавкой // Трение и износ. -2017 . - Т. 38, № 4. - С. 311-318.

10. Формирование композиционного покрытия NiCrBSi-TiC с повышенной абразивной износостойкостью методом газопорошковой лазерной наплавки / А. В. Макаров, Н. Н. Соболева, И. Ю. Малыгина, А. Л. Осинцева // Упрочняющие технологии и покрытия. - 2013. № 11 (107). - C. 38-44.

11. The tribological performances of a NiCrBSi-TiC laser-clad composite coating under abrasion and sliding friction / A. V. Makarov, N. N. Soboleva, I. Yu. Malygina, A. L. Osintseva // Diagnostics, Resource and Mechanics of materials and structures. - 2015. - Iss. 3. - P. 83-97. URL: http://dream-journal.org/Issues/2015-3/2015-3_33.html

12. Контактная выносливость $\mathrm{NiCrBSi}$ покрытий, полученных методом газопорошковой лазерной наплавки / Р. А. Саврай, А. В. Макаров, Н. Н. Соболева, И. Ю. Малыгина, А. Л. Осинцева // Обработка металлов. - 2014. - № 4 (65). - С. 43-51.

13. Eddy-current testing of fatigue degradation under contact loading of NiCrBSi coatings obtained through gas-powder laser cladding / R. A. Savrai, A. V. Makarov, E. S. Gorkunov, L. Kh. Kogan, N. N. Soboleva, I. Yu. Malygina, A. L. Osintseva // Russian Journal of Nondestructive Testing. - 2015. - Vol. 51, iss. 11. - P. 692-704. - DOI: 10.1134/S1061830915110042.

14. The behavior of gas powder laser clad NiCrBSi coatings under contact loading / R. A. Savrai, A. V. Makarov, N. N. Soboleva, I. Yu. Malygina, A. L. Osintseva // Journal of Materials Engineering and Performance. - 2016. - Vol. 25, iss. 3. - P. 1068-1075.

15. Eddy-current testing of the fatigue degradation of a gas powder laser clad $\mathrm{NiCrBSi}-\mathrm{Cr}_{3} \mathrm{C}_{2}$ composite coating under contact fatigue loading / R. A. Savrai, A. V. Makarov, E. S. Gorkunov, N. N. Soboleva, L. Kh. Kogan, I. Yu. Malygina, A. L. Osintseva, N. A. Davydova // AIP Conference Proceedings. - 2017. - Vol. 1915, no. 040049. - P. 1-4. - DOI: 10.1063/1.5017397.

16. Повышение микромеханических свойств и износостойкости хромоникелевого лазерного покрытия финишной фрикционной обработкой / А. В. Макаров, Н. Н. Соболева, Р. А. Саврай, И. Ю. Малыгина // Вектор науки ТГУ. - 2015. - № 4 (34). - С. 60-67.

17. Ходаковский В. М. Технологические аспекты выбора оборудования для лазерного упрочнения деталей // Вестник Морского государственного университета. Серия : Судостроение и судоремонт. - 2011. - Вып. 47. - С. 8-13.

18. Кострицкий В. В., Лисовский А. Л. Повышение поглощательной способности поверхностного слоя металла при лазерном воздействии с помощью поглощающих покрытий // Вестник Полоцкого государственного университета. Серия В : Промышленность. Прикладные науки. Машиностроение. - 2013. - № 3. - С. 97-101.

19. Шастин В. И. Пути повышения эффективности лазерного термоупрочнения железоуглеродистых сплавов // Вестник Алтайского государственного аграрного университета. 2015. - № 11 (133). - С. 117-121.

20. Промышленное применение лазеров / под ред. Г. Кебнера. - М. : Машиностроение, 1988. $-280 \mathrm{c}$.

21. Коваленко В. С., Головко Л. В., Черненко В. С. Упрочнение и легирование деталей машин лучом лазера. - Киев : Техника, 1990. - 191 с.

22. Климков Ю. М., Майоров В. С., Хорошев М. В. Взаимодействие лазерного излучения с веществом : учебное пособие. - М. : МИИГАиК, 2014. - 108 с.

23. Григорьянц А. Г., Шиганов И. Н., Мисюров А. И. Технологические процессы лазерной обработки : учебное пособие для вузов / под ред. А. Г. Григорьянца. - М. : Изд-во МГТУ им. Н. Э. Баумана, 2008. - 664 с.

24. Predoi D. A study on iron oxide nanoparticles coated with dextrin obtained by coprecipitation // Digest Journal of Nanomaterials and Biostructures. - 2007. - Vol. 2, no. 1. P. 169-173. 
25. Вайзман Ф. Л. Основы органической химии : учебное пособие для вузов / пер. с англ. под ред. А. А. Потехина. - СПб : Химия, 1995. - 464 с.

26. Криштал М. М., Ивашин П. В., Коломиец П. В. Использование технологии микродугового оксидирования при разработке ДВС с блоком цилиндров из алюминиевого сплава // Известия Самарского научного центра РАН. - 2010. - Т. 12, № 4. - С. 242-246.

27. Упрочнение алюминиевого сплава АЛ4 излучением $\mathrm{CO}_{2}$-лазера / В. Д. Кальнер, В. И. Волгин, В. М. Андрияхин, В. К. Седунов // Поверхность. Физика, химия, механика. 1982. - № 12. - С. 131-134.

28. Либенсон М. Н., Яковлев Е. Б., Шандыбина Г. Д. Взаимодействие лазерного излучения с веществом (силовая оптика). - Часть II : Лазерный нагрев и разрушение материалов : учебное пособие / под общ. ред. В. П. Вейко. - СПб. : НИУ ИТМО, 2014. - 181 с.

29. К Кузнецов П. М., Федоров В. А. Особенности формирования рельефа на поверхности металлов в зоне воздействия лазерного излучения // Вестник Тольяттинского государственного университета. - 2015. - Т. 20, № 4. - С. 872-877. 